\title{
Kuhn and the Question of Pursuit Worthiness
}

\author{
Dunja Šešelja and Christian Straßer \\ Centre for Logic and Philosophy of Science, Ghent University (UGent) \\ Blandijnberg 2, 9000 Ghent, Belgium \\ \{dunja.seselja, christian.strasser\}@UGent.be
}

\begin{abstract}
The aim of this paper is, on the one hand, to critically investigate Kuhn's stance on the assessment of the pursuit worthiness of scientific theories, and, on the other hand, to show the actuality of some of Kuhn's points on this issue, in view of their critical analysis. To this end we show that Kuhn presents certain tools, which may help scientists to overcome communication breakdowns when engaging in the process of rational deliberation regarding the question whether a theory is worthy of further pursuit. These tools are persuasion, translation and interpretation. However, we argue that the perspective of epistemic semantic monism present in Kuhn's work obstructs the full applicability of these tools. We show that dropping this perspective makes the notions of persuasion and interpretation more fruitful, and moreover, allows for a pluralism of scientific theories and practices that complements the pluralism based on disagreement among scientists, emphasized by Kuhn.

Keywords: Thomas Kuhn, pursuit worthiness, theory choice, epistemic monism, methodological pluralism.
\end{abstract}

\section{Introduction}

The context of pursuit refers to a period in which scientists pursue a new idea/scientific object/hypothesis/theory/etc. and preliminarily evaluate its pursuit worthiness. For example, Larry Laudan defines it as a context specific for the emergence of a new research tradition, in which scientists begin to pursue, explore and develop a theory long before it is qualified to be accepted over its older rivals (Laudan, 1977, p. 110). As such, the context of pursuit combines the aspects of both discovery and justification, which have often been discussed in view of Hans Reichenbach's distinction between the context of discovery and the context of justification (Reichenbach (1938)). On the one hand, the context of pursuit regards the process of theory development, while on the other hand, the normative question whether a given scientific idea is worthy of pursuit is posed in it.

However, the question of pursuit worthiness can be posed not only with regard to emerging scientific theories, but also with regard to accepted theories. In the latter case we are interested in their further heuristic capacity (see Nickles $(2006))$. Moreover, we may ask whether certain aspects of an overthrown scientific theory are still worthy of pursuit, such as its constituent epistemic objects (see Chang (2011)). 
The aim of this paper is twofold. First, to critically investigate Kuhn's stance on the assessment of the pursuit worthiness of scientific theories, and second, to show the actuality of some of Kuhn's points on this issue, in view of their critical analysis.

The significance of our research questions goes both ways as well. First, Kuhn's work is important for the topic of pursuit worthiness since it emphasizes and explicates tensions in communication and understanding that can appear among scientists working in different scientific paradigms. This issue is of direct relevance for the question of how a scientist working in one paradigm can assess the pursuit worthiness of a theory belonging to a different paradigm and hence for the question whether or to what extent scientists can engage in a rational deliberation process concerning this topic. There are serious threats for various prerequisites of the process of rational deliberation that can arise due to these tensions between paradigms. For instance, in order not to talk at cross-purposes participants in such debates should have a shared set of standards to which they can refer to and which can help them to evaluate and communicate pros and cons of the given candidates. Moreover, scientists should have cognitive access to the given candidates so that they are able to understand them.

Second, focusing on the topic of pursuit worthiness can highlight certain aspects of Kuhn's views on the rationality underlying theory change before and after scientific revolutions, which have so far been insufficiently clarified in the literature on his work. Evidently, before a scientific revolution arises an alternative paradigm must have gone through the context of pursuit in which it was developed and positively evaluated as being worthy of pursuit 1 Similarly, after a scientific revolution takes place the question arises whether (certain parts of) the old paradigm are still worthy of pursuit.

Hence, in this paper we will present the following. First, we will show in which way Kuhn explicates the assessment of pursuit worthiness of scientific theories, and at which point in the development of a theory scientists engage in a discussion over its pursuit worthiness (Section 2). We will then show that Kuhn's notions of persuasion (Section 3), translation and interpretation (Section 4) are fruitful tools for the rationality underlying the reasoning of a scientist who is to evaluate a paradigm incommensurable with the one in which she is currently working. Nevertheless, we will show that Kuhn's tools are burdened by a type of epistemic semantic monism, also pointed by other authors who discussed his work (Section 5). We will argue that in order for Kuhn's tools to be suitable for facilitating the understanding and communication among scientists regarding the topic of pursuit worthiness, the epistemic semantic monism has to be dropped.

\footnotetext{
${ }^{1}$ It is important to notice that the relationship between paradigms and theories is ambiguous in Kuhn's work already due to the ambiguous nature of the former notion. For a detailed discussion on this ambiguity we refer the reader to (Hoyningen-Huene, 1993, Chapter 4.). For the purposes of this paper it will suffice to use these two terms loosely, allowing for the assessment of pursuit worthiness to be applicable to both terms (paradigms and theories). Where a given paradigm is a unit of appraisal that encompasses one or more theories, the assessment of its pursuit worthiness is also essentially informed by the pursuit worthiness of these respective theories.
} 


\section{Kuhn on the Evaluation of Pursuit Worthi- ness}

The main obstacle in understanding Kuhn's points on the evaluation of pursuit worthiness comes from the fact that they fall under his general discussion of theory choice. Hence, we will first take a look at a few places that indicate that Kuhn considered this type of assessment to be different from the one regarding theory acceptance.

The prospective character Let us begin with a couple of places from The Structure of Scientific Revolutions:

... if a new candidate for paradigm had to be judged from the start by hard-headed people who examined only relative problemsolving ability, the sciences would experience very few major revolutions ... But paradigm debates are not really about relative problemsolving ability, though for good reasons they are usually couched in those terms. Instead, the issue is which paradigm should in the future guide research on problems many of which neither competitor can yet claim to resolve completely. A decision between alternate ways of practicing science is called for, and in the circumstances that decision must be based less on past achievement than on future promise. The man who embraces a new paradigm at an early stage must often do so in defiance of the evidence provided by problem-solving. He must, that is, have faith that the new paradigm will succeed with the many large problems that confront it, knowing only that the older paradigm has failed with a few. A decision of that kind can only be made on faith. (Kuhn, 1962 [1996], p. 157-158, italics added.)

The parts in italics indicate that Kuhn here obviously speaks of the pursuit worthiness of paradigms. Such an assessment of a new candidate concerns its future promise, which is based on faith that it will succeed in solving some important current problems. In other words, what is at stake here is not the current epistemic performance of a paradigm, but rather its epistemic fertility for future development. The type of appraisal we are interested in is not a retrospective but a prospective one (see Whitt (1990, 1992), Nickles (2006, 2009), Šešelja \& Straßer (201x) 2

\footnotetext{
${ }^{2}$ Different authors (e.g. those just mentioned) have emphasized different values as indices of pursuit worthiness, but explanatory and heuristic virtues of the given theory have often been considered as some of the crucial ones. For instance, the capability of the theory to offer explanations that its rivals have not managed to offer so far can be seen as such an indicator. This explanatory virtue is different from the one usually required for theory acceptance, where we are not only interested in what the theory can explain, but also in what it cannot explain, that is, in its explanatory anomalies. In contrast, when we evaluate whether a theory is worthy of pursuit, instead of focusing on its explanatory anomalies, we are rather interested in its programmatic character which indicates that the investigation can proceed in spite of the current anomalies and towards their resolution. Hence, we are interested in the prospective values, which allow for a prospective assessment, rather than a retrospective one, which is typical for the context of acceptance.
} 
The two phases of pursuit Kuhn goes on to argue that a crisis is important precisely in order to allow for a new candidate to be at all noticed. He then adds:

But crisis alone is not enough. There must also be a basis, though it need be neither rational nor ultimately correct, for faith in the particular candidate chosen. Something must make at least a few scientists feel that the new proposal is on the right track, and sometimes it is only personal and inarticulate aesthetic considerations that can do that. Men have been converted by them at times when most of the articulable technical arguments pointed the other way.

This is not to suggest that new paradigms triumph ultimately through some mystical aesthetic. On the contrary, very few men desert a tradition for these reasons alone. Often those who do turn out to have been misled. But if a paradigm is ever to triumph it must gain some first supporters, men who will develop it to the point where hardheaded arguments can be produced and multiplied. And even those arguments, when they come, are not individually decisive. Because scientists are reasonable men, one or another argument will ultimately persuade many of them. But there is no single argument that can or should persuade them all. Kuhn, 1962 [1996], p. 158, italics added.)

In these passages Kuhn indicates that there are two stages of the evaluation of pursuit worthiness of a paradigm. On the one hand, the first supporters of a paradigm feel that the new proposal is on the right track. Kuhn here departs from rational reasons one might have for evaluating a new paradigm as initially worthy of pursuit. He allows for "personal and inarticulate aesthetic considerations", which may turn out to have been misleading, to serve as the basis of the evaluation. On the other hand, if the first supporters develop the paradigm further, it may reach the point where arguments can finally be used. This is the second stage of the evaluation of pursuit worthiness, which proceeds in rational terms, and where the process of persuasion can begin.

Paul Hoyningen-Huene (1993) captures these two steps as the first two out of three types of reasons that according to Kuhn underlie theory choice: $i)$ the reasons relevant to the very first adherents of a theory, ii) the reasons generated while working on a new theory, which eventually bring more and more members of the community to adopt that theory, and iii) the reasons which are decisive for the choice of the entire community to accept the new theory (p. 239). The first set of reasons refers to the work on the theory prior to its public presentation. The second set refers to the stage at which the theory enters the public discourse.

Such a distinction between the two steps in the evaluation of pursuit worthiness has been pointed out by others as well. For instance, Thomas Nickles (Nickles, 1980, p. 9-10) distinguishes between generation and pursuit as the first two phases of a scientific research 3 Generation concerns the production of an idea which initially seems worthy of a second look in relation to the problem at hand. It represents a minimal achievement that may be confined to an individual thinker, but which nevertheless can be formulated in view of certain constraints. In contrast, pursuit is the phase in which a scientist is discovering

\footnotetext{
${ }^{3}$ The third and final phase is acceptance.
} 
an idea that is worthy of pursuit, i.e. worthy of some expenditure or time and effort by the scientific community.

Two claims of pursuit worthiness Let us now distinguish between two types of claims of pursuit worthiness. One claim of pursuit worthiness concerns the situation in which a scientist is confronted with the question: "Should I pursue this theory?". This question regards the assessment of pursuit worthiness as a research directive. This is obviously predominant in (though not restricted to) the first phase discussed above. For both Kuhn (including Hoyningen-Huene's reading of him) and for Nickles, this first phase falls in the domain of reasons underlying decisions concerning research activities of an individual scientist. For instance, Kuhn speaks of "a decision between the alternate ways of practicing science", of "embracing a new paradigm", and of its first supporters "developing it" themselves (rather than merely evaluating it).

However, there is another type of claims of pursuit worthiness, that refer to an assessment of pursuit worthiness as an evaluative stance. These claims regard the question: "Would pursuing this theory be in the epistemic interest of science/the respective scientific domain?". Note that a claim of pursuit worthiness as an evaluative stance bares no necessary practical commitments regarding one's own research. A scientist working in one paradigm may evaluate a theory from another paradigm as worthy of pursuit without necessarily concluding that she herself should engage in its pursuit. Indeed, more than one theory (each of which may belong to a different paradigm) may be worthy of pursuit at the same time 4

This latter type of pursuit worthiness claims are important as soon as a theory enters a public discourse (and hence, in the second phase indicated by Kuhn). This is the point when a scientist can evaluate not only her own research path, but also those of other scientists, and engage in a rational discussion on their pursuit worthiness. She may not only be interested in the question what she is to pursue, but also, how cognitively resp. epistemically attractive other rivaling inquiries are. Moreover, this is the point when she may receive critical feedback from other scientists about her own research and its pursuit worthiness. We will come back to Kuhn's neglect of pursuit worthiness as an evaluative stance in Section 3 .

In summary, we have seen that Kuhn underlines the importance to prospectively evaluate the pursuit worthiness of theories, that he establishes two phases of scientific inquiry in which this question arises, and finally, that he recognizes the pursuit worthiness concerning the research directive of a scientist. The question remains how we are to evaluate whether the claims regarding the pursuit worthiness of a given theory are cognitively and/or epistemically warranted. How can a rational assessment be safeguarded from the biases rooted in one's

\footnotetext{
${ }^{4}$ It is important to notice that the above distinction is not exhaustive when it comes to dif-

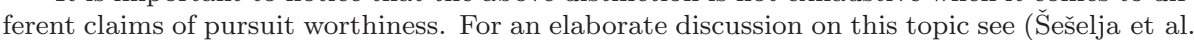
(2012)). Moreover, since cognitive issues were of primary interest in Kuhn's work, we speak here only of cognitive pursuit worthiness. It is important to keep in mind though that the assessment of pursuit worthiness may usually include a broader set of both cognitive and non-cognitive values, in which case we can speak of practical pursuit worthiness. The latter should not be confused with cognitive pursuit worthiness as a research directive, since practical pursuit worthiness also appears in the form of an evaluative stance and (a decision making form of) a research directive.
} 
own research framework? How can different applications and understandings of shared standards be bridged so that they don't lead to a communication breakdown? To this end Kuhn introduced certain tools that may help in facilitating the understanding among scientists working in different paradigms. We will examine these tools in the following two sections.

\section{Argumentation as Persuasion}

Persuasion and theory choice In response to the criticism accusing him of irrationality underlying theory choice, Kuhn argues in the Postscript to the Structure that his stance does not entail that proponents of incommensurable paradigms cannot communicate with each other, nor that in their debates there can be no recourse to good reasons (Kuhn, 1962 [1996], p. 199). He rejects accusations according to which such reasons are ultimately personal, subjective or irrational. He explains that his point was rather to show that debates over theory choice cannot be cast in a form that fully resembles a logical or mathematical proof (Ibid.).

More precisely, Kuhn rejects what we have elsewhere called the strong notion of rationality 5 governing theory choice. According to this notion, by applying the criteria that are shared by the scientific community, one obtains a unique choice of a scientific theory. In other words, this notion assumes that all scientists will have the same preference order on theories on the basis of a shared set of criteria with which they evaluate them. However, Kuhn argues that discussions among scientists instead of such an "algorithmic path" often take the path of persuasion:

...the superiority of one theory to another is something that cannot be proved in the debate. Instead, I have insisted, each party must try, by persuasion, to convert the other. ... Nothing about that relatively familiar thesis implies either that there are no good reasons for being persuaded or that those reasons are not ultimately decisive for the group. Nor does it even imply that the reasons for choice are different from those usually listed by philosophers of science: accuracy, simplicity, fruitfulness, and the like. What it should suggest, however, is that such reasons function as values and that they can thus be differently applied, individually and collectively, by men who concur in honoring them. (p. 198-199)

Kuhnian persuasion would not be very useful for our discussion were it restricted to the question of theory acceptance. As the following quotation shows, Kuhn considered it also applicable for the assessment of pursuit worthiness:

Recognizing that criteria of choice can function as values ... allows the standard criteria to function fully in the earliest stages of theory choice, the period when they are most needed but when, on the traditional view, they function badly or not at all. (Kuhn, 1977, p. 331, italics added)

\footnotetext{
${ }^{5}$ See $($ Śšělja \& Straßer, 2009, p. 323).
} 
Thus, persuasion as a form of argumentation based on cognitive criteria that function as values, is applicable to the earliest stages of theory assessment. We should not overlook though that Kuhn describes this assessment as theory choice. Moreover:

These five characteristics - accuracy, consistency, scope, simplicity, and fruitfulness - are all standard criteria for evaluating the adequacy of a theory. ... I agree entirely with the traditional view that they play a vital role when scientists must choose between an established theory and an upstart competitor. Together with others of much the same sort, they provide the shared basis for theory choice. (Kuhn, 1977, p. 322, italics added.)6

Hence, the key cognitive issue that confronts scientists when they are to assess an upcoming theory is the choice of a research framework which they will individually pursue. They are to choose between the established theory and the newcomer theory. It wouldn't make much sense if choice here meant that scientists are to accept one of the two rivals as a fully developed paradigms, simply due to the fact that the newcomer is not sufficiently developed to undergo such an evaluation. Nor can Kuhn refer to scientists making a claim of pursuit worthiness as an evaluative stance, for in that case, no choice would have to be made: a scientist may evaluate both the dominant theory and its new rival as worthy of pursuit in this sense. The most plausible interpretation seems to be that a scientist is to choose a research directive, and thus to make a claim of pursuit worthiness as a research directive.

In light of what we have just said, when Kuhn writes that:

To persuade someone is, I take it, to convince him that one's own view is superior and ought therefore supplant his own. (Kuhn, 1962 [1996], p. 203)

we can conclude that 'supplanting of one view by another' seems to refer to a shift of a scientist from one paradigm to another. Faced by a choice between two paradigms, a scientist is to make a decision which of them she is to work in.

Persuasion regarding an evaluative stance of pursuit worthiness There are various types of convictions and associated commitments of a scientist $S$ with respect to which this supplanting and convincing can take place:

C1. the conviction that a theory $T$ is true/adequate or (epistemically or cognitively) the best in a certain domain and hence superior to other candidates;

C2. the conviction that a theory $T$ is the best for $S$ to investigate;

C3. the conviction that a theory $T$ is worthy of pursuit (though it may not necessarily be the best option for $S$ to work in and it may not be the best theory in the given domain).

The first question is usually raised in the context of acceptance: there we are interested in the best theory (though, of course, being the best is not sufficient for being accepted since it may only be the best of a poor bunch). The second

${ }^{6}$ See also Kuhn, 2000, p. 96). 
question concerns pursuit worthiness as a research directive, while the third question concerns pursuit worthiness as an evaluative stance. Note that (C1) and (C2) are of a more exclusive character than (C3): one usually settles for one theory (in some cases maybe two, but rarely more theories) to which the commitment that is associated with (C1) resp. (C2) is directed. However, many more theories than the one which is considered the best, resp. the one a scientist is currently working in may be worthy of pursuit. Hence, the commitment that comes with convictions of type (C3) are less exclusive and more pluralistic in nature. As our analysis above suggests, Kuhn doesn't distinguish between (C1) and (C2), while he neglects (C3).

Moreover, unlike questions (C1) and (C2), the claim of pursuit worthiness as an evaluative stance does not require a comparative assessment in the sense that the overall pursuit worthiness of theories needs to be compared (see also Whitt (1990)). Instead, the indices of theory promise (see e.g. Whitt (1992), Šešelja \& Straßer (201x)) are assessed in view of the cognitive horizon, which is constituted by other rivaling theories. The cognitive horizon is constituted -among other things- by the current subject domain of a given discipline, by the problems that scientists tackle, by the anomalies and difficulties they face, by respected scientific methods, etc. The cognitive horizon need not be homogeneous: various sub-disciplines may have different preferences e.g. on what counts to be a good scientific method, a good explanation etc. Moreover, a newly pursued theory may challenge this status quo in some ways. For instance, one of the indices of pursuit worthiness can be formulated as the question whether the theory is able to offer certain novel explanations or predictions, that is, to explain or predict phenomena that its rivals are not able to. Hence, we may have to compare certain features of the new theory with those of its rivals, which constitute the cognitive horizon. However, that does not mean we are comparing the overall cognitive promise of these theories.

Indeed, scientists will not necessarily agree about which theories are worthy of pursuit and which are not in this latter (evaluative) sense of the term. They may still need to persuade one another about their respective stances. But this type of persuasion does not require that they supplant their convictions in the sense of (C1) and (C2). Persuasion suitable for this type of claims may begin by convincing the opponent that the theory in question has certain cognitive properties which are conducive of its pursuit worthiness. Hence, the opponent (who originally evaluated this theory as not worthy of pursuit) might be convinced that her view on the theory needs to be supplanted by the new insights. In so far, we can still say with Kuhn that to persuade someone is to convince her that one's view (regarding the pursuit worthiness of the given theory) is superior and ought thus to supplant her own. However, the opponent need not supplant her views regarding the pursuit worthiness (or acceptance) of other theories, including the one(s) she is currently pursuing.

Whether we speak of claims of pursuit worthiness as research directives or as evaluative stances, a question that comes up in either case is: how are scientists to proceed towards understanding each other regarding such claims if their respective theories are incommensurable? How is the process of persuasion at all possible in face of such differences in their worldviews? In particular, with regard to the claims of pursuit worthiness as evaluative stances we can ask: How is the rationality of the claims of pursuit worthiness safeguarded in face of 
incommensurable theories? How are scientists able to evaluate whether a claim stating that a given theory is epistemically worthy of pursuit - is a cognitively or epistemically warranted claim? To this end Kuhn introduces additional tools, which we will explore in the following section.

\section{Translation and Interpretation}

Translation In order to explicate how the process of persuasion is at all possible among scientists working in different paradigms, Kuhn introduces "a potent tool both for persuasion and for conversion", namely translation:

However incomprehensible the new theory may be to the proponents of tradition, the exhibit of impressive concrete results will persuade at least a few of them that they must discover how such results are achieved. For that purpose they must learn to translate... (Kuhn, 1977, p. 339, italics added)

With the term 'translation' one has to be careful as a scholar of Kuhn's work since in different contexts in Kuhn's writings this terms has different meanings. For instance 'translation' may refer to the skill of a translator, i.e., somebody who already masters two languages and, given a text in one of them, is able to "produce an equivalent text in the other language" (Kuhn, 2000, p. 38). Then again, 'equivalent text' may mean different things. In his criticism of Kitcher (Kuhn, 2000, pp. 33-57) it is conceived of as a substitution procedure that enables one to replace concepts, names, predicates, etc. in one language with correlates in another language so that extensional equivalence is achieved. Kuhn argues that this is suboptimal to acquire a full understanding since it proceeds irrespective of the intensional, associative, and epistemic deep structure of the translated language. This criticism gives a more refined interpretation of 'equivalent text', one that often amounts to an unreachable ideal, especially in the context of incommensurable theories.

For the passage above we suggest that 'learning to translate' is to be understood in terms of a didactic tool in the process of language acquisition. Hence, in view of certain research results scientists can, according to Kuhn, find a new theory worthy of further understanding and learning about. To this end, they can learn to translate terms from this theory to the one they are already experienced in. Note that translation here does not presuppose that one already speaks both languages, that is, knows both theories 7

\footnotetext{
${ }^{7}$ Kuhn also points out that

... despite the incompleteness of their communication, proponents of different theories can exhibit to each other, not always easily, the concrete technical results achievable by those who practice within each theory. Little or no translation is required to apply at least some value criteria to those results. (Accuracy and fruitfulness are most immediately applicable, perhaps followed by scope. Consistency and simplicity are far more problematic.) (Kuhn, 1977, p. 339, italics added)

Moreover, for some scientists these considerations may be decisive to change their research directive:

... each language community can usually produce from the start a few concrete research results that, though describable in sentences understood in the same way by both groups, cannot yet be accounted for by the other community
} 
The following passage gives - at least prima facie- more interpretative leeway for what 'translators' may refer to:

The men who experience such communication breakdowns must, however, have some recourse. . . . both their everyday and most their scientific world and language are shared. ... what the participants in a communication breakdown can do is recognize each other as members of different language communities and then become translators. (Kuhn, 1962 [1996], p. 201-202, italics added)

Here the talk about 'becoming translators' could well be understood in the first meaning discussed above: i.e., in terms of mastering both languages and being able to produce equivalent texts. However, this interpretation is barred due to the impossibility of translating incommensurable theories: after all, incommensurability means intranslatability 8

Going-native and conversion Translation is not the only tool Kuhn suggests that is useful for understanding another research paradigm. Indeed, the process of translation may give rise to a deeper engagement with the other paradigm, namely to 'going-native':

To translate a theory or a worldview into one's own language is not to make it one's own. For that one must go native, discover that one is thinking and working in, not simply translating out of, a language that was previously foreign. That transition is not, however, one that an individual may make or refrain from making by deliberation and choice, however good his reasons for wishing to do so. Instead, at some point in the process of learning to translate, he finds that the transition has occurred, that he has slipped into the new language without a decision having been made. (Kuhn, 1962 [1996], p. 204, italics added)

Hence, in the process of language acquisition one slips from merely translating into a more intimate engagement with the new language, that is, one becomes native, begins to think in the new language and makes it "one's own". Of course, only in this modus are we able to get a deeper understanding of the subtleties of the new candidate, similarly to the process of learning a foreign tongue. Moreover, the better one's understanding of the new candidate, the more qualified and informed will be the judgment concerning its pursuit worthiness.

Now, the question arises whether a scientist could be working in one framework, and yet learn (the language of) the other one to a degree that she is also

in its own terms. If the new viewpoint endures for a time and continues to be fruitful, the research results verbalizable in this way are likely to grow in number. For some men such results alone will be decisive. They can say: I don't know how the proponents of the new view succeed, but I must learn, whatever they are doing, it is clearly right. (p. 203, italics added)

Kuhn here suggests that some initial results of a theory can only be described by the scientists working in a rivaling paradigm, but they cannot be accounted for, explained in their own terminology. In order for that to be possible, scientists need to learn the new theory.

8 "The claim that two theories are incommensurable is then the claim that there is no language, neutral or otherwise, into which both theories, conceived as sets of sentences, can be translated without residue or loss." (Kuhn, 2000, p. 36). 
fluent or "native" in the new candidate? Kuhn's answer seems to be negative due to the captivating character of going-native which leads to conversion:

... the possibility of translation does not make the term 'conversion' inappropriate. In the absence of a neutral language, the choice of a new theory is a decision to adopt a different native language and to deploy it in a correspondingly different world. That sort of transition is, however, not one which the terms 'choice' and 'decision' quite fit, though the reasons for wanting to apply them after the event are clear. Exploring an alternative theory by techniques like those outlined above, one is likely to find that one is already using it (as one suddenly notes that one is thinking in, not translating out of, a foreign language). At no point was one aware of having reached a decision, made a choice. That sort of change is, however, conversion, and the techniques which induce it may well be described as therapeutic, if only because, when they succeed, one learns one had been sick before. (Kuhn, 1970, p. 277)

Kuhn here tells us that the result of going-native is conversion - a process in which one not only internalizes the new theory and is "at home in the world it helps to shape" (Ibid.) but also acquires a commitment of the exclusive type (C1) resp. (C2) (see Section 3). In this case, a scientist has not only begun to work in a new theoretical framework, but she has adopted it in a "therapeutic" manner, realizing that she previously was "sick". Hence, conversion -as explicated in the previous paragraph- also includes the shift of an evaluative perspective, where the new framework becomes the basis of all cognitive assessments in the given domain.

Therefore, in both of these modes of understanding (i.e. translation and going-native) the cognitive commitments $(\mathrm{C} 1),(\mathrm{C} 2)$ and $(\mathrm{C} 3)$ are conflated and confined to one paradigm - to which the rival is being translated, or into which the scientist has been converted.

Interpretation But what about the possibility that scientists learn a new theory without necessarily becoming epistemically committed to it resp. without adopting it? In his later work (Kuhn, 2000, pp. 33-57) he characterizes such a process of learning as interpretation. He contrasts interpretation with translation (conceived as the skill of a translator, see our discussion above) in the following way:

[interpretation] is an enterprise practiced by historians and anthropologists, among others. Unlike the translator, the interpreter may initially command only a single language. At the start, the text on which he or she works consists in whole or in part of unintelligible noises or inscriptions. ... If the interpreter succeeds, what he or she has in the first instance done is learn a new language... Whether that language can be translated into the one with which the interpreter began is an open question. Acquiring a new language is not the same as translating from it into one's own. Success with the first does not imply success with the second. (p. 38, italics added)

Translation is, of course, only the first resort of those who seek comprehension. Communication can be established in its absence. 
But where translation is not feasible, the very different processes of interpretation and language acquisition are required. (p. 53)

Hence, interpretation is a type of going-native that does not imply conversion, that is, it has no epistemically captivating character. Kuhn, however, describes interpretation as a tool used by historians of science and anthropologists, rather than something that is useful for scientists themselves. But why couldn't scientists become interpreters as well? This question becomes especially interesting if we think of the claims of the type C3, which do not require a full comparative assessment. In contrast to Kuhnian translation, which employs two languages and is thus more suitable for a comparison of two theories, we could say that the aim of his notion of interpretation is understanding of one theory in view of the cognitive horizon of the time. The answer to the above question seems to lie in Kuhn's epistemic semantic monism, which we will take a look at in the following section.

$$
* * *
$$

In the introduction we gave two examples of obstacles that can appear in the process of rational deliberation concerning questions of pursuit. The first one concerned the existence of shared standards in the evaluation of theories. The second obstacle concerned the existence of insurmountable comprehension gaps. With regard to the former one, we have seen in Section 3 that, when it comes to persuasion, Kuhn calls upon the existence of shared standards that serve as the basis of this deliberation process. With regard to the latter, we have seen in this section that Kuhn offers two tools to overcome these gaps: translation on the one hand and going-native on the other hand. However, there is a certain tension that comes along with these tools and rational deliberation. The problem is that going-native seems to subvert any rational deliberation due to its non-deliberative character. Deliberation presupposes that we weigh reasons for and reasons against the given idea and on the basis of this weighing make a choice or decision. However, the notion of going-native is "not one which the terms 'choice' and 'decision' quite fit". Where language acquisition should be a tool to gain a better understanding, which should in turn be a tool for the rational weighing of reasons, for Kuhn the process of language acquisition makes the rational weighing superfluous since it is itself sufficient to transform the scientist's conviction.

We have contrasted going-native with Kuhn's notion of interpretation. Due to its lack of an epistemically captivating character interpretation may be more apt to serve as a tool for rational deliberation.

\section{Kuhn's Epistemic Semantic Monism and the Question of Pluralism}

We have already pointed out a number of places where Kuhn speaks of theory assessment in the context of theory choice construed either along the lines of theory acceptance or the choice of a practical directive (rather than an evaluative stance) with regard to newly developing scientific theories. Already in Section 2 we have seen Kuhn arguing that in debates about which paradigm should 
in future guide the research "a decision between alternate ways of practicing science is called for". Moreover, we have seen him offering translation or goingnative (leading to conversion) as tools that scientists can use in debates in the context of pursuit in order to bridge communication breakdowns.

We were puzzled by two peculiarities: first, Kuhn's disregard of the possibility of pursuit worthiness as an evaluative stance that entails no commitments regarding one's own research (see Section 3), and second, Kuhn's insistence on the epistemically captivating character of a scientist's going-native which we contrasted with his notion of interpretation (see Section 4.) In this section we will root the lack of these options in what we shall call the perspective of epistemic semantic monism present in Kuhn's work. The key idea of this perspective is that an individual scientist or a group of scientists is epistemically confined only to one theoretical framework and its taxonomy. On the one hand, it is an epistemic monism since it refers to the epistemic (or cognitive) perspective of a scientist (or a group of scientists), which serves as the basis of her (their) cognitive assessments. On the other hand, it is a semantic monism since it is essentially rooted in language and its taxonomic structure constituting the given paradigm as well as the world in which the scientist works (see, e.g., Kuhn, 2000, p. 52,77)).

Epistemic monism and pursuit worthiness That a certain type of epistemic monism is present in Kuhn's work has been pointed out by others as well. For instance, Watkins (Lakatos \& Musgrave, 1970, p. 34) introduced his "paradigm-monopoly thesis" that "a scientist cannot, while under the sway of one paradigm, seriously entertain another paradigm".

Similarly, Hasok Chang (2011) ascribes epistemic monism to Kuhn, pointing out that the key idea of such a monism is that "if we have the correct theory in place, all other (genuinely different) theories in that domain must be eliminated" (p. 426) 9 Chang goes on to argue that even Imre Lakatos, who depicts scientific development in terms of multiple research programmes, motivated this monism by means of a competition that enables scientists to eventually make the right choice.

But why are we so obsessed with choice? Why do we need to choose between different alternatives in a strong, exclusive sense? Why can't "choice" be a more relaxed matter of each scientist or each group of scientists deciding which avenue of investigation to take, without implying that all the other avenues are inferior and should be closed off? (Ibid.)

Indeed, Kuhn not only speaks of theory choice as a choice of a cognitive commitment of type (C1) and/or (C2), but he even suggests that the term "choice" is misleading in this case, since the way a scientist adopts the given framework is usually not even voluntary (see also (Hoyningen-Huene, 1993, p. 257-258)).

Darrell Rowbottom (2011) points out that according to Kuhn, work within a paradigm as a disciplinary matrix is possible only if that paradigm is taken for granted (p. 118):

\footnotetext{
${ }^{9}$ However, this is not the whole truth since there is also a pluralist side to Kuhn as we discuss below.
} 
Kuhn appears to have thought that scientists would not be motivated to tackle such esoteric problems (or puzzles) without rigid belief - or even faith - in the paradigm.

This claim may also be somewhat dubious, however, because it is possible to do things for extrinsic reasons. I could learn to recite a poem in order to impress a prospective lover without having any interest in verse or metre, just as a scientist could be content to solve puzzles, in the short term, in order to support himself and slowly build a reputation which would lead to some of his potentially revolutionary ideas being taken more seriously by his peers. (p. 119, italics added)

Rowbottom points out that there may be good reasons for a scientist to work on a theory (see $(\mathrm{C} 2)$ ) while not being epistemically committed to it in a stronger sense (see (C1)). Even though we can agree with Rowbottom that engaging in puzzle solving may be independent from the adoption of the given disciplinary matrix, it is important to notice that extrinsic reasons are not necessarily required for such an engagement. A scientist may simply conclude that making any stronger epistemic claims (such as an overall acceptance, or a belief resp. faith in its truthfulness, or the claim that it is the best resp. preferred among the given alternatives, etc.) about the given theory would be unwarranted since premature, but this need not prevent her to evaluate it as worthy of pursuit (either in terms of a research directive or in terms of an evaluative stance). Moreover, scientists may have intrinsic epistemic resp. cognitive reasons for making claims of pursuit worthiness as evaluative stances, which do not presuppose their full epistemic or practical commitment to the framework in question. These may be various prospective values that indicate that a theory is promising to be further investigated. For instance, if one evaluates the predictive power of the theory in question or its inferential connections with theories from other domains, she may conclude that this candidate is promising to be further researched, even though she may not have any practical commitments regarding it (that is, she may assess it as worthy of pursuit without making a decision to engage in its pursuit).

Epistemic monism and methodological pluralism However, this discussion does not imply that Kuhn disregards the value of pluralism in scientific theory and practice. In contrary, he has emphasized more than once that due to the necessary uncertainty regarding the future of scientific theories, it is of vital importance for the progress of science that more than one research path remains explored. In other words, Kuhn's position is a monist one regarding the cognitive commitments of an individual scientist (resp. of groups of scientists working within the same paradigm), while he is a methodological pluralist in the sense that he finds the plurality of pursued paths fruitful for the scientific enterprise.

Nevertheless, the presence of the former makes his pluralism restricted. More precisely, by disregarding scientists' claims of pursuit worthiness as evaluative stances, Kuhn limits pluralism to a disagreement among scientists:

Before the group accepts it, a new theory has been tested over time by the research of a number of men, some working within it, 
others within its traditional rival. Such a mode of development, however, requires a decision process which permits rational men to disagree, and such disagreement would be barred by the shared algorithm which philosophers generally have sought. If it were at hand, all conforming scientists would make the same decision at the same time.... With standards of acceptance set too low, they would move from one attractive global viewpoint to another, never giving traditional theory an opportunity to supply equivalent attractions. With standards set higher, no one satisfying the criterion of rationality would be inclined to try out the new theory, to articulate it in ways which showed its fruitfulness or displayed its accuracy and scope. I doubt that science would survive the change. Kuhn, 1977, p. 332, italics added)

The talk about 'trying theories' and 'moving to attractive viewpoints' suggests that the assessment of pursuit worthiness here comes as a practical directive regarding a concrete research path of an individual scientist. Different scientists may find different theories more worthy of pursuit than others, and hence each of them may decide to engage in the pursuit of a different one. In order to assure such a diversity of pursued theories, Kuhn argues that a disagreement among scientists in their evaluation of pursuit worthiness of the given theories is necessary 10

The fact that the pursuit of different paths by scientists leads to scientific pluralism is trivial. However, what deserves some more discussion is the claim that a disagreement among scientists is essential to pluralism. First of all, it is not clear where the disagreement really lies in case the subject matter concerns the pursuit worthiness of theories as research directives. There is no disagreement in X's conclusion "I should pursue theory $T_{1}$ " and Y's conclusion "I should pursue theory $T_{2}$ ". Rather, a disagreement would only concern a more general claim concerning the pursuit worthiness of some theory that is not relativized to one's own research activity. But that concerns claims of pursuit worthiness as evaluative stances.

However, making a claim of pursuit worthiness as an evaluative stance does not require a "shared algorithm" which delivers as an output a unique theory that is worthy of pursuit. In contrary, both (some) new candidates as well as the traditional rival could simultaneously be assessed as worthy of pursuit. Scientists may still have different preferences concerning the question which theories they find most worthy to work on. This way a discipline may be characterized by a plurality of pursued theories without any disagreement being necessary for it. Hence, Kuhn's dilemma from the previous quote can be avoided. Of course, there may still be disagreement about the pursuit worthiness of some candidates. However, this disagreement seems not anymore essential to pluralism.

Therefore, in addition to a pluralism emerging from such a dissent, there is also a pluralism that can emerge out of an agreement regarding the claims of pursuit worthiness as evaluative stances. An individual scientist in this case evaluates a theory as worthy of pursuit without necessarily engaging in its actual pursuit. She can say: "Even though I prefer to explore theory $T_{1}$, theory $T_{2}$ is worthy of pursuit as well, and it is rational for another scientist to pursue it.".

\footnotetext{
${ }^{10}$ Also, in Hoyningen-Huene's reading of Kuhn, such a disagreement is considered as vital for the development of science (Hoyningen-Huene, 2006, p. 128).
} 
Nevertheless, in order for such a pluralism to be possible, epistemic semantic monism has to be removed. Without its burden, Kuhnian tools - persuasion, translation and interpretation- can receive a role in the rational deliberation regarding the claims of pursuit worthiness as evaluative stances.

\section{Conclusion}

In this paper we have presented Kuhn's stance on the question of pursuit worthiness as well as the actuality of some of his points for the contemporary discussions on this issue. On the one hand, we have shown that Kuhn explicates tools that may help scientists to overcome communication breakdowns when engaging in the process of rational deliberation regarding the question whether a theory is worthy of further pursuit. More precisely, even when confronted with an incommensurable paradigm, scientists can resort to the tools of persuasion, translation, and interpretation in order to learn the new theory and to thus be able to assess its pursuit worthiness. On the other hand, we have shown that if these tools are to be fully apt for this task, the assumption of epistemic semantic monism present in Kuhn's work has to be abandoned. That way, persuasion becomes the process in which scientists aim at convincing each other to change their views regarding their respective evaluative stances of pursuit worthiness, while interpretation becomes suitable not only for historians of science, but also for scientists themselves. Furthermore, such an approach gives rise to a pluralism of scientific theories and practices that complements Kuhn's pluralism, based on dissensus among scientists as its conditio sine qua non.

It is interesting to notice that a Kuhnian conception of pluralism comes with a peculiar asymmetry: the one between, on the one hand, the methodologist/philosopher of science who upholds the merits of having a plurality of scientific accounts, and, on the other hand, the scientist who, being an epistemic monist, tries to convince other scientists of her account being the most valuable option to choose. Since the scientists cannot agree on the one most valuable option they split into different camps and pluralism is the outcome. The pluralist's golden apple, its very vital principle is dissensus. Thrown into the scientific community it causes it to flourish healthy, just like Erin's apple in the Greek myth causes the goddesses to compete and show themselves from their best sides while awaiting Paris' ultimate choice of the best one. And here we are reminded of the epistemic monist's focus on theory choice discussed earlier.

In this paper we have sketched an alternative type of pluralism where the asymmetry between the pluralist methodologist and the monist scientist disappears. In this alternative view scientists are allowed to be pluralists as well. We have argued that as soon as scientists evaluate theories in terms of their pursuit worthiness instead of in terms of theory acceptance and instead of in terms of individual research directives, they may as well judge a plurality of theories as worthy of pursuit. This allows for a more harmonious view on science where the division between the methodologist's pluralist topdown view and the scientist's monist view is unnecessary. It allows for and values pluralism by giving back to each individual scientist the vivid curiosity that fuels her imagination, where she may say for not just one, but for many ideas: "This is interesting, somebody should pursue it further...". 


\section{References}

Chang, H. (2011). The persistence of epistemic objects through scientific change. Erkenntnis, 75, 413-429.

Hoyningen-Huene, P. (1993). Reconstructing Scientific Revolutions: Thomas S. Kuhn's Philosophy of Science. Chicago, London: The University of Chicago Press.

Hoyningen-Huene, P. (2006). Context of discovery versus context of justification and thomas kuhn. In Schickore \& Steinle (2006).

Kuhn, T. (1962 [1996]). Structure of Scientific Revolutions. (3rd ed.). Chicago: The University of Chicago Press.

Kuhn, T. (1970). Reflections on my critics. In Lakatos \& Musgrave (1970).

Kuhn, T. (1977). The Essential Tension: selected studies in scientific tradition and change. Chicago: University of Chicago press.

Kuhn, T. (2000). The Road since Structure. Chicago: University of Chicago Press.

Lakatos, I., \& Musgrave, A. (Eds.) (1970). Criticism and the Growth of Knowledge. Cambridge, MA: Cambridge University Press.

Laudan, L. (1977). Progress and its Problems. Routledge \& Kegan Paul Ltd.

Nickles, T. (1980). Introductory essay: Scientific discovery and the future of philosophy of science. In T. Nickles (Ed.), Scientific Discovery: Case Studies (pp. 1-59). Dordrecht: D. Reidel Publishing Company.

Nickles, T. (2006). Heuristic appraisal: Context of discovery or justification? In Schickore \& Steinle (2006).

Nickles, T. (2009). Life at the frontier: The relevance of heuristic appraisal to policy. Axiomathes, 19, 441-464.

Reichenbach, H. (1938). Experience and Prediction. University of Chicago Press.

Rowbottom, D. P. (2011). Kuhn vs. popper on criticism and dogmatism in science: a resolution at the group level. Studies In History and Philosophy of Science Part A, 42, 117124.

Schickore, J., \& Steinle, F. (Eds.) (2006). Revisiting Discovery and Justification: Historical and philosophical perspectives on the context distinction. Netherlands: Springer.

Šešelja, D., Kosolosky, L., \& Straßer, C. (2012). Rationality of scientific reasoning in the context of pursuit: drawing appropriate distinctions. Philosophica, accepted for publication.

Šešelja, D., \& Straßer, C. (2009). Kuhn and coherentist epistemology. Studies in History and Philosophy of Science, 40, 322-327. 
Šešelja, D., \& Straßer, C. (201x). Epistemic justification in the context of pursuit: A coherentist approach. Synthese, accepted for publication.

Whitt, L. A. (1990). Theory pursuit: Between discovery and acceptance. In PSA: Proceedings of the Biennial Meeting of the Philosophy of Science Association (pp. 467-483). volume 1.

Whitt, L. A. (1992). Indices of theory promise. Philosophy of Science, 59, $612-634$ 